\title{
A study of Wireless Communications Systems based on Multiple Correspondence Analysis
}

\author{
Samira Achki \\ Faculté des Sciences et Techniques \\ Morocco \\ s.ichki@gmail.com \\ Fatima Gharnati \\ La Faculté des Sciences Semlalia de Marrakech \\ Morocco \\ f.gharnati@uca.ma
}

ABSTRACT: Today there are many wireless communication systems that meet the needs of users, however those systems remains a revolutions regarding the quality and security of service level. In this article, we discuss the comparison of the performance of various wireless communication systems such as WIFI, WIMAX, UMTS, HSDPA, GPRS, GSM, 3G and LTE using a multiple correspondence analysis (MCA) to classify and identify each system by their strong and weak mechanisms in terms of performance based on frequency band, rate, range, access technology, mobility, latency, modulation type and transmission type, in the aim to intended the characteristics that can increase the relevance and quality of the wireless communication system.

Keywords: IEEE 802.11g, IEEE 802.11e, IEEE 802.11m, GSM, GPRS, EDGE, UMTS, HSDPA, HSPA+, 3G, LTE, 4G, ACM

Received: 17 September 2018, Revised 3 November 2018, Accepted 12 November 2018

DOI: $10.6025 /$ jnt/2019/10/1/1-8

(C) 2019 DLINE. All Rights Reserved

\section{Introduction}

In recent years, several standards and wireless communication technologies have emerged and established themselves in our daily life, to such an extent that it is impossible today to imagine a world without applications or wireless services. These technologies have a role increasingly important in many aspects of our society and we can meet them everywhere: at home, office, outdoors, in transportation, etc [1]. The purpose of these technologies depends on not only communications, but also education, entertainment, navigation, health and trade. 
Currently, several wireless standards and technologies exist and respond to specific needs and still in revolution, that is why this work is concerned with the study of the technical specification, in order to find the best among them, we concentered in this article on the classification and sorting of these different systems based on multiple correspondence analysis which is detect the performance measure that increases the quality of the system, and this is the process of ACM method used.

1.1 Process Multiple Correspondence Analysis

In this context we schematized a process of method ACM for the catch of ranking by using software SPSS.

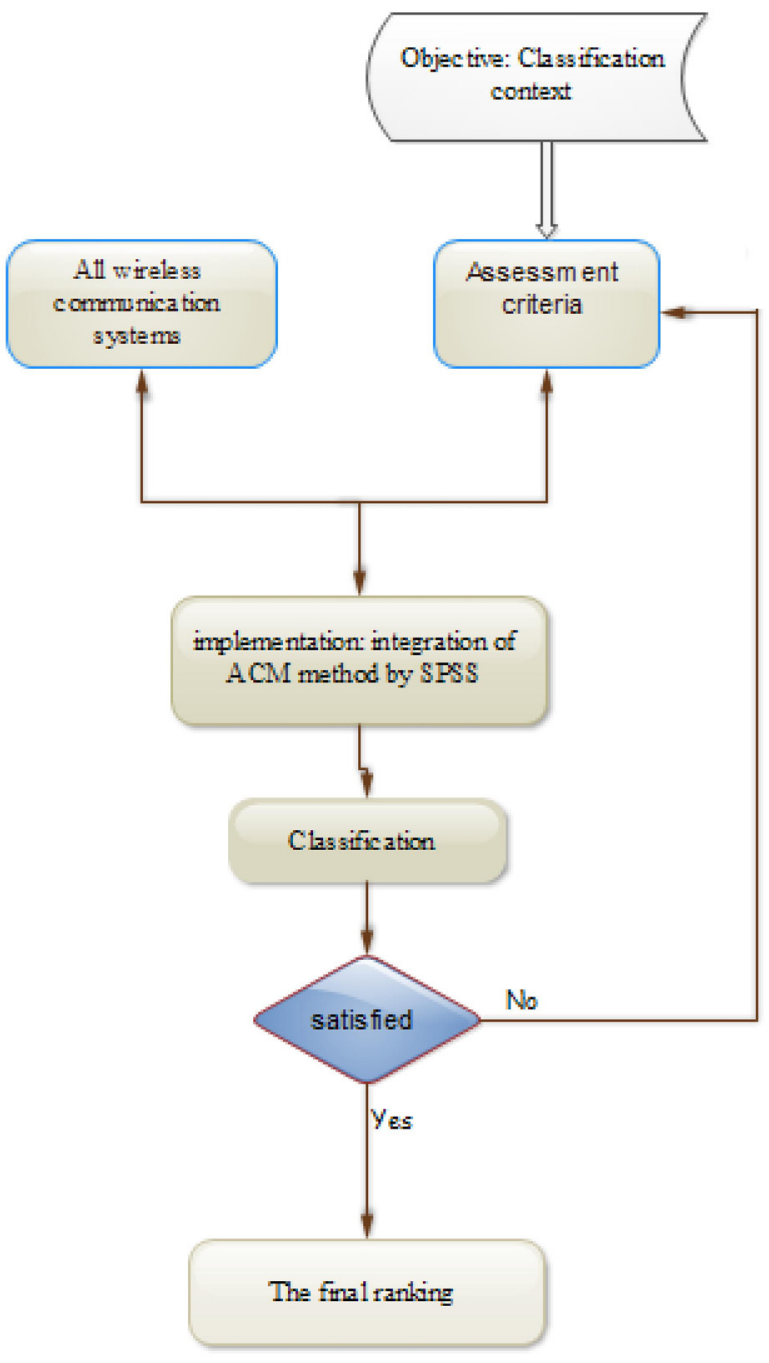

Figure 1. Process multiple correspondence analysis

\section{Different Technique of Wireless Communications Systems and Criteria}

\subsection{Wireless Systems Communication}

Wireless communication systems grow with time according to several criteria related to advanced technologies and science, taking into account the needs of users. [2]

Wireless Systems Communication are as follow:

- WIFI [3] [4]: Wireless Fidelity

-WIMAX802.11g [5]: Worldwide Interoperability for Microwave Access 


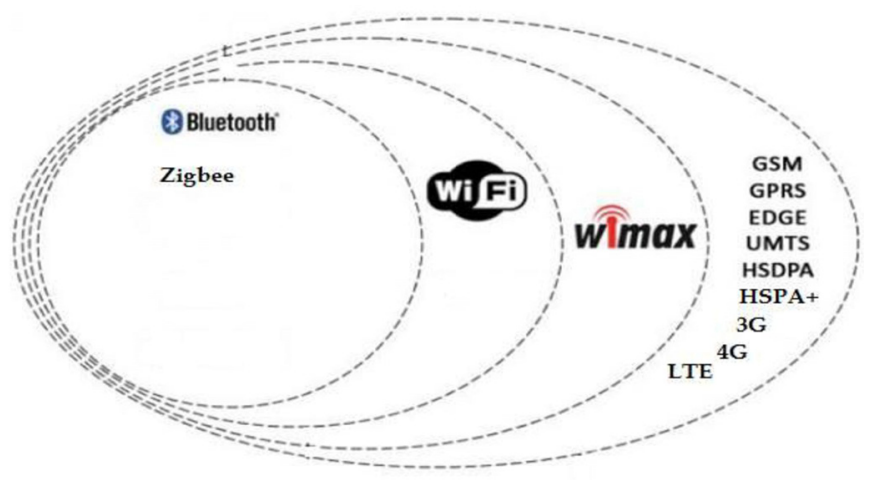

Figure 1. Wireless systems communication

-UMTS [6]: Universal Mobile Telecommunications System

- HSPDA [7]: High Speed Downlink Packet Access

- GPRS [8]: General Packet Radio Service

- GSM [9]: : Global System for Mobile

-3G [10]:Third generation

- LTE [11]: Long Term Evolution

-4G [12]: The fourth generation

- EDGE [13]: Enhanced Data Rates for GSM Evolution

- HSPA+ [14]: Evolved High-Speed Packet Access

-WIMAX802.11m [15]: Worldwide Interoperability for Microwave Access

\subsection{Different Characteristic}

Wireless communication systems are characterized by:

- Frequency Band (Mhz)[16]: are groupings of radio frequencies that are used by mobile networks to communicate with mobile phones. The frequency bands that a phone supports determine to a large degree where and on which networks it can be used.

- Range (Km) 17]: Range or coverage is the geographic area where the station can communicate. Broadcasters and telecommunications companies frequently produce coverage maps to indicate to users the station's intended service area.

- Throughputs (Mbits/s) [18]: is a measure of how many units of information a system can process in a given amount of time. It is applied broadly to systems ranging from various aspects of computer and network systems to organizations.

-Access Technology [19]: Access methods are multiplexing techniques that provide communications services to multiple users in a single-bandwidth wired or wireless medium.

- Mobility $(\mathbf{K m} / \mathbf{h})$ [20]: is the capability of moving or being moved. The term is used in wireless telecommunications to indicate that a wireless device or a service may be used while moving.

- Latency (ms) [21]: is the delay from input into a system to desired outcome; the term is understood slightly differently in various contexts and latency issues vary from one system to another.

- Modulation [22] : is the addition of information (or the signal) to an electronic or optical carrier. Modulation can be applied to direct current (mainly by turning it on and off), to alternating current, and to optical signals. 
- Commutation [23]: A synonym for switching in computer networking and telecommunications.

\begin{tabular}{|c|c|c|c|c|c|c|c|c|}
\hline $\begin{array}{l}\text { Wireless } \\
\text { Systems } \\
\text { Communication }\end{array}$ & $\begin{array}{l}\text { Frequency } \\
\text { Band }\end{array}$ & Range & $\begin{array}{l}\text { Through } \\
\text { puts }\end{array}$ & $\begin{array}{l}\text { Acces } \\
\text { Technology }\end{array}$ & Mobility & Latency & Modulation & $\begin{array}{c}\text { Commu- } \\
\text { tation }\end{array}$ \\
\hline WIFI & 2,4 & 0,1 & 54 & CSMA & 4,8 & 130 & OFDMDSSS & Package \\
\hline WIMAX802.11g & 5,8 & 6,4 & 70 & OFDMA & 120 & 50 & 64QAMQPSKQAM16 & Package \\
\hline UMTS & 2,1 & 10 & 2 & CDMA & 250 & 250 & QPSK & Package \\
\hline HSDPA & 2,1 & 30 & 14.4 & WCDMA & 300 & 60 & QPSK16QAM & Package \\
\hline GPRS & 1,8 & 10 & 0,14 & CDMA & 150 & 300 & GMSK & Package \\
\hline GSM & 1,8 & 5 & 0,01 & TDMA & 150 & 300 & GMSK & Package \\
\hline $3 \mathrm{G}$ & 2,1 & 15 & 1,9 & CDMA & 200 & 100 & 8PSK & $\begin{array}{l}\text { Circuit/ } \\
\text { Package }\end{array}$ \\
\hline LTE & 2,6 & 30 & 326 & OFDMA & 350 & 100 & 64QAM16QAMQPSK & Package \\
\hline $4 \mathrm{G}$ & 8 & 30 & 1000 & OFDMA & 350 & 50 & 64QAM16QAMQPSK & Package \\
\hline EDGE & 1,9 & 12 & 0,38 & TDMA & 200 & 300 & 8PSK & Package \\
\hline HSPA+ & 0,01 & 7,4 & 14 & CDMA & 300 & 50 & 64QAM & Package \\
\hline WIMAX802.11m & 6 & 10 & 1000 & OFDMA & 350 & 30 & 64QAM16QAMQPSK & Package \\
\hline
\end{tabular}

Table 1. The Criterion of the Wireless Communication System

\section{Comparative and Classification of Wireless Communications Systems Based on Multiple Correspondence Analysis}

\subsection{Principle of ACM}

Since we have several wireless communication systems and defined by different parameters, we chose to use the ACM method to classify each system through their powerful characters. And to get out the best among them in terms of criteria already specifiers.

In statistics, multiple correspondence analysis (MCA) is a data analysis technique for nominal categorical data, used to detect and represent underlying structures in a data set. It does this by representing data as points in a low-dimensional Euclidean space. The procedure thus appears to be the counterpart of principal component analysis for categorical data. [24] MCA can be viewed as an extension of simple correspondence analysis (CA) in that it is applicable to a large set of categorical variables.

\subsection{Application of ACM and Results}

\begin{tabular}{|l|l|l|l|l|l|l|l|l|}
\hline & $\begin{array}{l}\text { Frequency } \\
\text { Band (Mhz) }\end{array}$ & $\begin{array}{l}\text { Range } \\
\mathbf{( K m )}\end{array}$ & $\begin{array}{l}\text { Through } \\
\text { puts (Mbits/s) }\end{array}$ & $\begin{array}{l}\text { Access } \\
\text { Technology }\end{array}$ & $\begin{array}{l}\text { Mobility } \\
\text { (Km/h) }\end{array}$ & $\begin{array}{l}\text { Latency } \\
\text { (ms) }\end{array}$ & $\begin{array}{c}\text { Modu- } \\
\text { lation }\end{array}$ & $\begin{array}{c}\text { Commu- } \\
\text { tation }\end{array}$ \\
\hline $\begin{array}{l}\text { Frequency } \\
\text { Band (Mhz) }\end{array}$ & 1000 &, 291 &,- 001 &, 357 &, 506 &,- 668 &,- 421 &, 030 \\
\hline Range (Km) &, 291 & 1,000 &,- 629 &, 000 &, 628 &,- 358 &, 062 &,- 704 \\
\hline $\begin{array}{l}\text { Debit theorique } \\
\text { Mbits/s }\end{array}$ &,- 001 &,- 629 & 1,000 &, 308 &,- 417 &, 246 &, 087 &, 398 \\
\hline $\begin{array}{l}\text { Access } \\
\text { Technology }\end{array}$ &, 357 &, 000 &, 308 & 1,000 &, 371 &,- 439 &,- 489 \\
\hline
\end{tabular}




\begin{tabular}{|l|l|l|l|l|l|l|l|l|}
\hline Mobility (Km/h) &, 506 &, 628 &,- 417 &, 371 & 1,000 &,- 654 &,- 389 &,- 369 \\
\hline Latency (ms) &,- 668 &,- 358 &, 246 &,- 439 &,- 654 & 1,000 &, 525 &,- 160 \\
\hline Modulation &,- 421 &, 062 &, 087 &,- 489 &,- 389 &, 525 & 1,000 &,- 310 \\
\hline Commutation &, 030 &,- 704 &, 398 &, 023 &,- 369 &,- 160 &,- 310 & 1,000 \\
\hline Dimension & 1 & 2 & 3 & 4 & 5 & 6 & 7 & 8 \\
\hline Valeur Propre & 3,247 & 2,296 &, 953 &, 660 &, 368 &, 244 &, 143 &, 089 \\
\hline
\end{tabular}

Table 2. Correlations of the Transformed Variables

Those tables shown the correlation between the various criteria based on distance of chi-square, which measures the association between variables.

We noted that there is a strong association between the scope $(\mathrm{Km})$ and mobility $(\mathrm{km} / \mathrm{h})$, and similarly for the scope in $\mathrm{km}$ and theoretical flow but with a strong association negative.

\subsection{Table of Dimension}

\begin{tabular}{|l|l|c|}
\hline \multirow{2}{*}{} & \multicolumn{2}{|c|}{ Dimension } \\
\cline { 2 - 3 } & $\mathbf{1}$ & $\mathbf{2}$ \\
\hline Bande de frequence (ghz) &, 708 &, 325 \\
\hline Range (Km) &, 676 &,- 657 \\
\hline Throughputs (Mbits/s) &,- 453 &, 629 \\
\hline Access Technology &, 474 &, 545 \\
\hline Mobility (Km/h) &, 893 &,- 125 \\
\hline Latency (ms) &,- 826 &,- 320 \\
\hline Modulation &,- 542 &,- 580 \\
\hline COMMUTATION &,- 291 &, 782 \\
\hline
\end{tabular}

Table 3. Table of Dimension

According to this table we can see that the CMA gives us two factors, the first factor is highly positively correlated with the frequency bands $(\mathrm{GHz})$ and mobility correlate strongly negatively $\mathrm{km}$ and with latency in $\mathrm{ms}$, the second factor is correlated strongly - negatively with theoretical throughput Mbit / s and switching (see the graph below).

\subsection{Principal Standardisation of the Variable}

After the application of the MCA that aims to reduce the size of two factors, it is now conducting a classification technique on these two factors to build the class of Wireless Communications systems the more homogeneous, it is the hierarchical classification technique. 


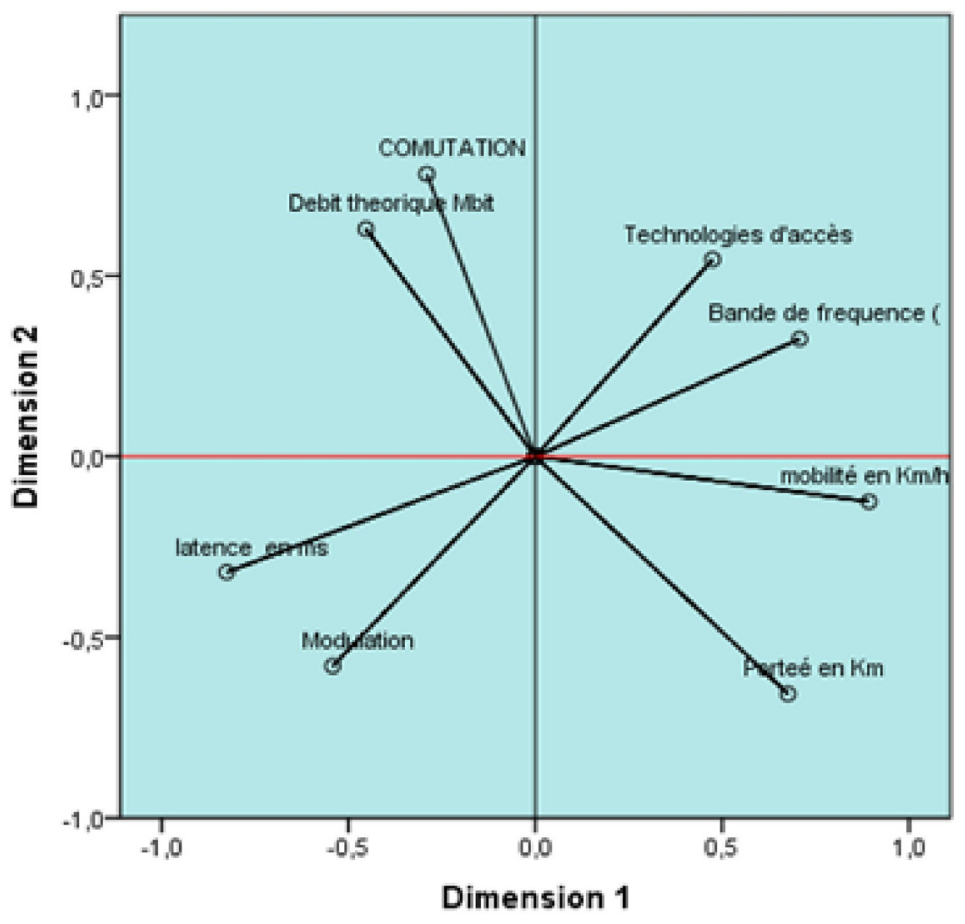

Figure 3. Principal standardisation of the variable

\subsection{Hierarchical Clustering}

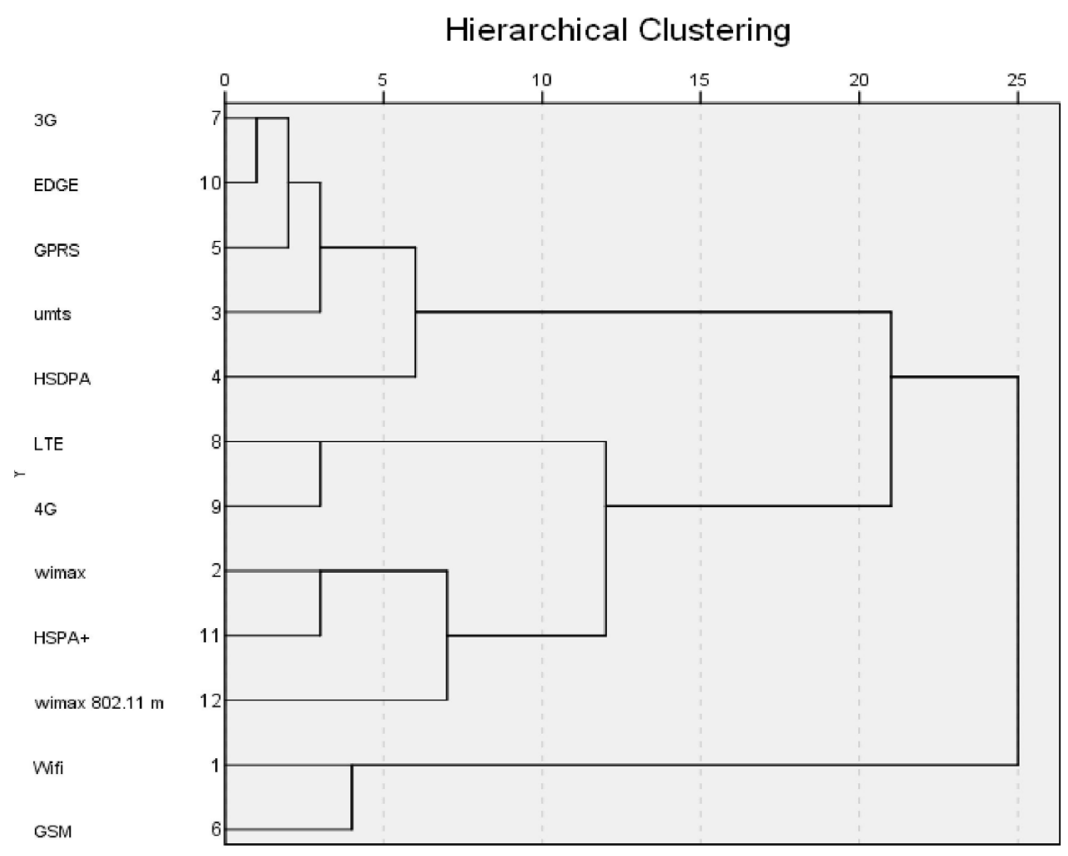

Figure 4. Hierarchical clustering

According to the hierarchical tree, we can create five classes (see fig): it is a factorial design where individuals are colored according to the classes, they belong (Fig):

So the classes obtained are: 
Class (1): GSM, WIFI

Class (2): Wimax802.11g, HSPA+

Class (3): 3G, EDGE, UMTS, GPRS, HSDPA

Class (4): LTE, $4 \mathrm{G}$

Class(5): Wimax $802.11 \mathrm{~m}$

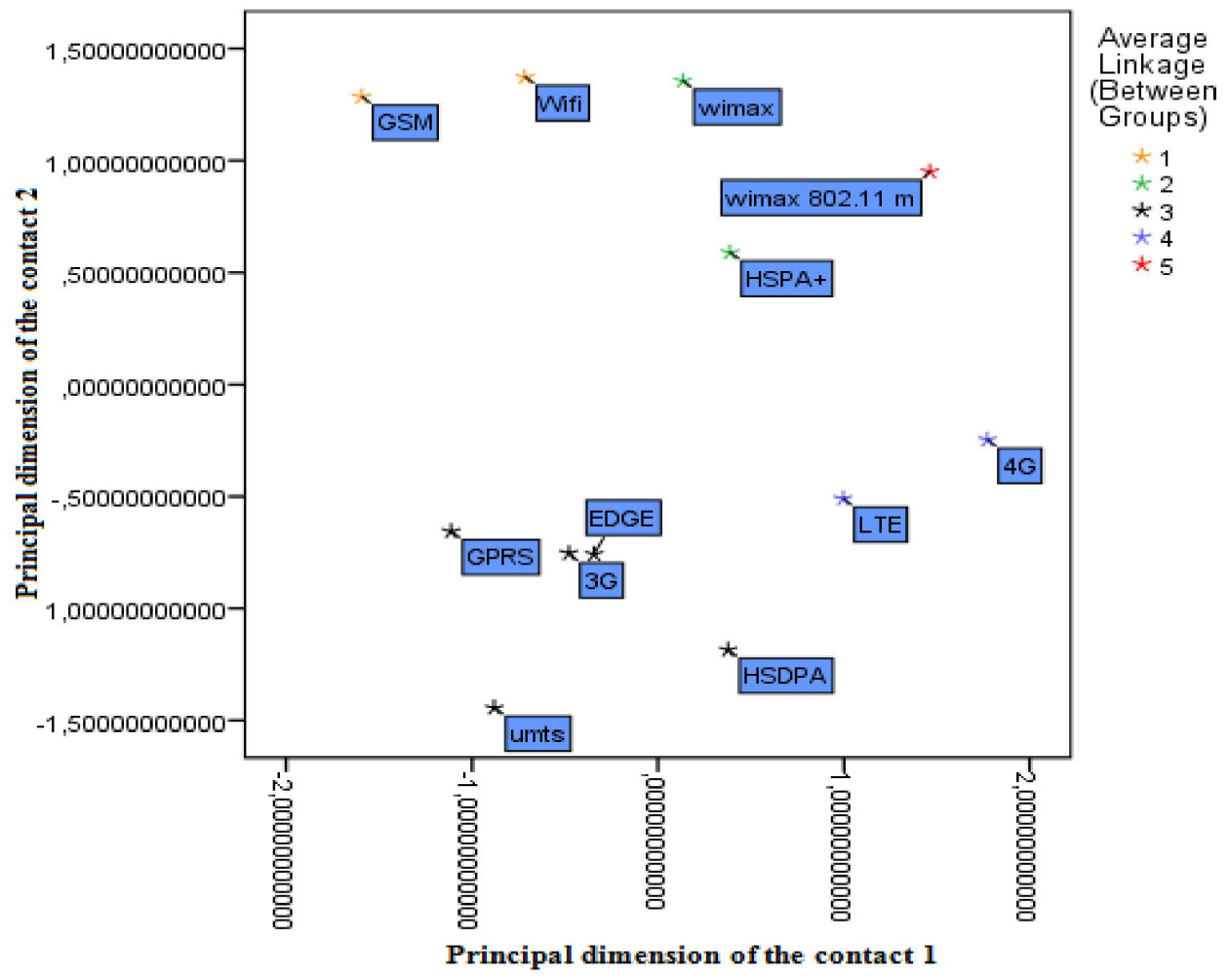

Figure 5. Double diagram

from the classes found we noted that:

- Class 1: Is characterized by the same switching and same theoretical throughput.

- Class 2: Is characterized by a medium frequency band and same access technology.

- Class 3: Characterized by a medium range and a significant lag.

- Class 4: Is characterized by better mobility and increased average theoretical speed and frequency band and low latency.

- Class 5: Is characterized by a strong band better mobility frequency, door and very low latency.

Therefore, we conclude that technical wimax $802.11 \mathrm{~m}$, LTE, 4G Class 4 and 5 are the most efficient technology among wireless system we proposed, which means that for assessing the performance of a communication system wireless we just need to evaluate the criterion of mobility the frequency band, scope, latency.

\section{Conclusions}

In this document, we presented wireless communication systems with their different performance characteristics. Compared with the multiple correspondence analysis, in fact the application of this method has confirmed that the selected wireless communication system and classified according to preference, the ACM method allows us to have the same result compared classical and theoretical methods. 


\section{References}

[1] Roux, Le., B., Rouanet, H. (2004). Geometric Data Analysis, From Correspondence Analysis to Structured Data Analysis. Dordrecht. Kluwer: p.180.

[2] Song, L., Kotz, D., Jain, R., He, X. (2004). Evaluating location predictors with extensive Wi-Fi mobility data. In: Proceedings of the 23nd Annual Joint Conference of the IEEE Computer and Communications Societies (INFOCOM).

[3] Greenacre, Michael., Blasius, Jörg. (editors) (2006). Multiple Correspondence Analysis and Related Methods. London: Chapman \& Hall/CRC

[4] Yoon, J., Noble, B., Liu, M., Kim, M. (2006). Building Realistic Mobility Models from Coarse-grained Traces, Mobisys.

[5] WiMAX Forum.(2008). Deployment of Mobile WiMAX Networks by Operators with Existing 2G \& 3G Networks, White Paper prepared by WiMAX Forum, 2008.

[6] UMTS FORUM. UMTS/HSPA broadband services in the $900 \mathrm{MHz}$ band: Strategy and Deployment, White Paper prepared by UMTS Forum, 2009.

[7] Fonollosa, J. R., Heikkila, M., Kermoal, J. P., Mestre, X., Pagés, A., Pollard, A., Schumacher, L., Wiesel, A., Ylitalo, J. (2002). Adaptive Modulation Schemes for MIMO HSDPA', to appear at the IST Mobile Summit, Thessaloniki, Greece, (June).

[8] 3GPP, BSS GPRS Protocol, 3GPPTS 08.18 v8.10.0, May 2002.

[9] Brasche, G., Walke, B. (1997). Concepts, Services, and protocols of the new GSM Phase 2+ General Packet Radio Service, IEEE Communications Magazine, August 1997, p. 94-104.

[10] Comparison on Performance Requirements, June 2008, submission to 3G Americas.

[11] Militano, L., Condoluci, M., Araniti, G., Iera, A. (2012). Bargaining Solutions for Multicast Subgroup Formation in LTE, IEEE 76th Vehicular Technology Conference(VTC-Fall), (September).

[12] Remy, G., Senouci, S., Jan, F., Gourhant, Y. (2012). Collection, dissemination and multi- IEEE International Conference on Communications (ICC).

[13] Nortel's GSM/EDGE Radio Access Network (GERAN) Evolution, 2006.

[14] Telenor HSPA and LTE - Future-proof Mobile Broadband Solutions by F R O D E B O H A G E N, JO R G E N B I N N I N G SBO.

[15] Yi, L., Miao, K., Liu, A. (2011). A Comparative Study of WiMAX and LTE as the Next Generation Mobile Enterprise Network, In: Advanced Communication Technology (ICACT), 2011 13th International conferenceon, February, p. 654-658.

[16] Vijayalaxmi, Thomas, J., Prihoda. (2008) Genetic Damage in Mammalian Somatic Cells Exposed to Radiofrequency Radiation: A Meta-analysis of Data from 63 Publications (1990-2005). Radiation Research 169 (5) 561-574.

[17] Pei, Yang., Xiumei, Yin., Huazhong, Yang. (2008). (Department of Electronic Engineering,Tsinghua University, Beijing 100084, China); An 80dB Dynamic Range, Modulator for Low-IF GSM Receivers, Journal of Semiconductors; 2008-02.

[18] Dabbagh, A. D., Ratasuk, R., Ghosh, A. (2008). On UMTSLTE Physical Uplink Shared and Control Channels, In: IEEE 68th VTC.

[19] The Wireless World Research Forum, http://www. wireless-world-research.org

[20] Lampropoulos, G., Salkintizis, A., Passas, N. (2008). Media-Independent Handover for Seamless Service Provision in Heterogeneous Networks, IEEE Communications Magazine, p.64 -71.

[21] Casado, Martin., Michael, J., Freedman. (2007). Peering through the shroud: the effect of edge opacity on ip-based client identification, In: Proceedings of the 4th USENIX conference on Networked systems design \& implementation, p.13-13, April 1113, 2007, Cambridge, MA

[22] Kabil, S., AitEssaid, B., AitOuahman, A., Elassali, R., Boukour, F. (2011). Analysis of UWB -OFDM system for vehicle to infrastructure communication, In: Proceedings of the 4th International Conference on Logistics (LOGISTIQUA), May 31-Jun. 3, IEEE Xplore Press Hammamet, p 430-433. DOI: 10.1109/LOGISTIQUA.2011.5939438

[23] https://tel.archives- ouvertes.fr/tel- 00407405

8

Journal of Networking Technology Volume 10 Number 1 March 2019 